\title{
Overwintering of Wheat Stripe Rust Under Field Conditions in the Northwestern Regions of China
}

\author{
Xiangming $\mathrm{Xu},{ }^{1,2}$ Lijie $\mathrm{Ma}^{3}$ and Xiaoping $\mathrm{Hu}^{1, \dagger}$ \\ ${ }^{1}$ State Key Laboratory of Crop Stress Biology for Arid Areas, College of Plant Protection, Northwest A\&F University, Taicheng \\ Road 3, Yangling 712100, China; ${ }^{2}$ Pest \& Pathogen Ecology, NIAB EMR, East Malling, West Malling, Kent ME19 6BJ, U.K.; \\ and ${ }^{3}$ Ordos Vocational College of Eco-Environment, Ordos 017010, China
}

\begin{abstract}
Stripe rust, caused by Puccinia striiformis f. sp. tritici Erikss., is an important disease of wheat worldwide. Identification of pathogen survival hot spots is important for predicting disease onset and subsequent spread to other regions, and such understanding is essential for developing integrated management strategies. We conducted field studies to determine the relationship of $P$. striiformis $\mathrm{f}$. sp. tritici overwintering potential to winter temperatures in 10 sites in the northwest of China in three growing seasons (2011-12, 2012-13, and 2013-14). The fungus survived better in wheat cultivars with stronger winter hardiness than in those with weaker winter hardiness. Windowpane analysis suggested that $P$. striiformis $\mathrm{f}$. sp. tritici winter survival is related to temperatures in the coldest period from mid-December to late January. $\beta$ Regression showed that $P$.

striiformis $\mathrm{f}$. sp. tritici winter survival was negatively related to the number of days with daily average temperature $<-2^{\circ} \mathrm{C}$ for cultivars with weak winter hardiness and $<-4^{\circ} \mathrm{C}$ for cultivars with both moderate and strong winter hardiness. Models developed under constant temperature experiments greatly underestimate the $P$. striiformis $\mathrm{f}$. sp. tritici overwinter potential under field conditions. This underestimation probably results from the possibility that $P$. striiformis $\mathrm{f}$. $\mathrm{sp}$. tritici in wheat tissues may have increased tolerance to low temperatures because of acclimation to gradual temperature changes under field conditions. The present models can be used to predict quantitative risks of $P$. striiformis f. sp. tritici overwintering in winter-wheat-growing regions for timely implementation of regional disease management strategies.
\end{abstract}

Stripe rust, caused by Puccinia striiformis f. sp. tritici Erikss., is an important disease of wheat worldwide (Chen 2005). Stripe rust is a polycyclic disease and $P$. striiformis f. sp. tritici produces urediniospores in multiple cycles. Airborne urediniospores can be dispersed over a long distance and may cause local, regional, and interregional epidemics (Wang et al. 2010). Annual cycles of stripe rust on winter wheat can be divided into four stages: oversummering, infection of seedlings in autumn, overwintering, and spring epidemic. P. striiformis f. sp. tritici has to overwinter in living host tissues ( $\mathrm{Li}$ and Zeng 2002; Sharp and Hehn 1963) and its survival over the winter is a key determinant of spring epidemics that directly result in crop losses (Gladders et al. 2007; Li and Zeng 2002; Sharma-Poudyal and Chen 2011). In cold high-altitude regions, $P$. striiformis f. sp. tritici is likely to overwinter in young green leaves as latent infection established in late autumn (Ma et al. 2016). P. striiformis f. sp. tritici mycelia inside green leaves may also be killed by low temperatures rather than through death of green leaves (Ma et al. 2015).

The ability to predict pathogen survival potential may enable timely implementation of integrated disease management strategies to reduce inoculum sources and prevent the formation of disease foci. Therefore, pathogen oversummering or overwintering areas have large epidemic consequences on local, regional, and interregional scales for disease prediction and management. For instance, summer and winter survival regions for $P$. striiformis $\mathrm{f}$. sp. tritici have been used to devise stripe rust management strategies in China. Yearround survival areas such as southern Gansu and northwestern

${ }^{\dagger}$ Corresponding author: Xiaoping Hu; E-mail: xphu@nwsuaf.edu.cn

Funding: This work was supported by the National Key Research and Development Program of China (2018YFD0200402 and 2016YFD0300702), the National Key Basic Research Program of China (2013CB127700), the National Natural Science Foundation of China (31071640 and 31271985), and the UK Science Technology Facility Council (STFC) funded UK-China Newton project (ST/N006852/1, ST/N006712/1, and ST/N006836/1).

Accepted for publication 7 September 2018.

() 2019 The American Phytopathological Society
Sichuan are considered stripe rust hot spots because these regions were associated with evolution of new races and high pathogenic variability (Li and Zeng 2002).

Temperature is the main limiting factor for P. striiformis f. sp.tritici survival in summer and winter because the pathogen cannot survive extreme cold or hot conditions (Sharma-Poudyal et al. 2014). Warm winters favor $P$. striiformis f. sp. tritici survival in infected leaves whereas severe winters do not allow the pathogen's survival (Grabow et al. 2016). The low limit of air temperature for $P$. striiformis f. sp. tritici to overwinter (November to February in China and North America) is believed to be around -6 to $-7^{\circ} \mathrm{C}$ (monthly mean) (Sharma-Poudyal et al. 2014; Shen and Wang 1962; Zeng and Luo 2006). Potential $P$. striiformis f. sp. tritici overwintering areas in China have been identified (Ma et al. 2005; Shen and Wang 1962) based on the data from field observations. However, recent field observations suggest that the overwintering boundary may have been gradually pushed toward the northwest (Pan et al. 2011; Yao et al. 2014), which may partially result from climate changes in recent times (Fang et al. 2012). In addition to low temperatures, wind chill may also result in reduced $P$. striiformis $\mathrm{f}$. sp. tritici overwintering potential (Ma et al. 2016). Many models have been developed to describe the relationship between winter temperature and stripe rust epidemics based on field observations (Coakley and Line 1981; Coakley et al. 1982, 1988) and were further revised (Sharma-Poudyal and Chen 2011). A model based on winter climatic conditions has been developed to predict $P$. striiformis f. sp. tritici overwintering potential on a categorical scale for winter-wheat-growing regions in the United States (Sharma-Poudyal et al. 2014). The negative effect of low temperature on $P$. striiformis f. sp. tritici overwintering may be alleviated to a certain extent by snow: a minimum snow cover of $7.6 \mathrm{~cm}$ may be sufficient to protect winter wheat from winter kill. The importance of environment during the winter months on $P$. striiformis f. sp. tritici survival was also noted in Europe (Papastamati and van den Bosch 2007; Te Beest et al. 2008).

We recently established a quantitative relationship in $P$. striiformis f. sp. tritici overwintering potential to temperature, based on the data obtained from constant and fluctuating temperature regimes under controlled conditions (Ma et al. 2015, 2017). P. striiformis f. sp. tritici survival in cultivars with strong winter hardiness at $0^{\circ} \mathrm{C}$ and $-5^{\circ} \mathrm{C}$ was greater than in those with weak winter hardiness. However, such 
differences in $P$. striiformis f. sp. tritici survival among cultivars were negligible when temperatures were $\leq-10^{\circ} \mathrm{C}$. Logistic models satisfactorily described the relationship of $P$. striiformis f. sp. tritici survival in attached leaves to temperature and winter hardiness. The relationship of $P$. striiformis $\mathrm{f}$. sp. tritici survival to temperature is nonlinear, particularly in the range of -5 to $-10^{\circ} \mathrm{C}$ (Ma et al. 2015), which was further confirmed by controlled fluctuating temperature studies (Ma et al. 2017). In parallel to these controlled studies, we monitored $P$. striiformis f. sp. tritici overwintering on cultivars with different winter hardiness as well as temperature during the winter in three seasons (2010-11, 2011-12, and 2012-13). This study identified the relationship of $P$. striiformis $\mathrm{f}$. sp. tritici overwintering to winter temperature in winter wheat under field conditions.

\section{Materials and Methods}

Sites and wheat varieties. Field experiments were conducted in three seasons-2011-12, 2012-13, and 2013-14-at seven, eight, and eight sites (fields), respectively, in Gansu and Qinghai Provinces, China (Fig. 1; Table 1). At each site, a USB logger (Lascar EL-USB$2^{+}$; Martel Electronics Corporation) was used to record hourly temperature and humidity from 1 December to 10 March of the next year.
The logger was placed at $5 \mathrm{~cm}$ above the ground. Several loggers failed to log the data for the complete period every year. For these sites, daily average temperature values recorded by a local meteorological station were used instead. For 8 of the 23 site-year combinations, complete data were recorded by the USB loggers. For all other sites, we had to use data recorded by local weather stations.

In the 2011-12 season, $P$. striiformis $\mathrm{f}$. $\mathrm{sp}$. tritici was only assessed in commercial winter-wheat fields whereas, in the 2012-13 and 2013-14 seasons, P. striiformis f. sp. tritici was monitored in experimental plots at each site where wheat plants were inoculated with $P$. striiformis f. sp. tritici in the autumn (Table 1). The experimental design was the same as that previously reported (Ma et al. 2016). At each site, four varieties (Table 1) were sown within a single plot (10 by $20 \mathrm{~m}$ ), with each variety occupying $50 \mathrm{~m}^{2}$ ( 2.5 by $\left.20 \mathrm{~m}\right)$. Two common varieties were used in all years at all sites: Xiaoyan 22 (XY22, weak winter hardiness) and Xinong 979 (XN979, moderate winter hardiness). The other two varieties were from the local regions and, hence, could differ between sites. At each site, two strips ( 0.15 by $20 \mathrm{~m}$ ) of cultivar Mingxian 169 (MX169, weak winter hardiness, highly susceptible to stripe rust) were planted. MX169 plants were inoculated in early autumn to act as an inoculum source for other varieties to initiate autumn infection.
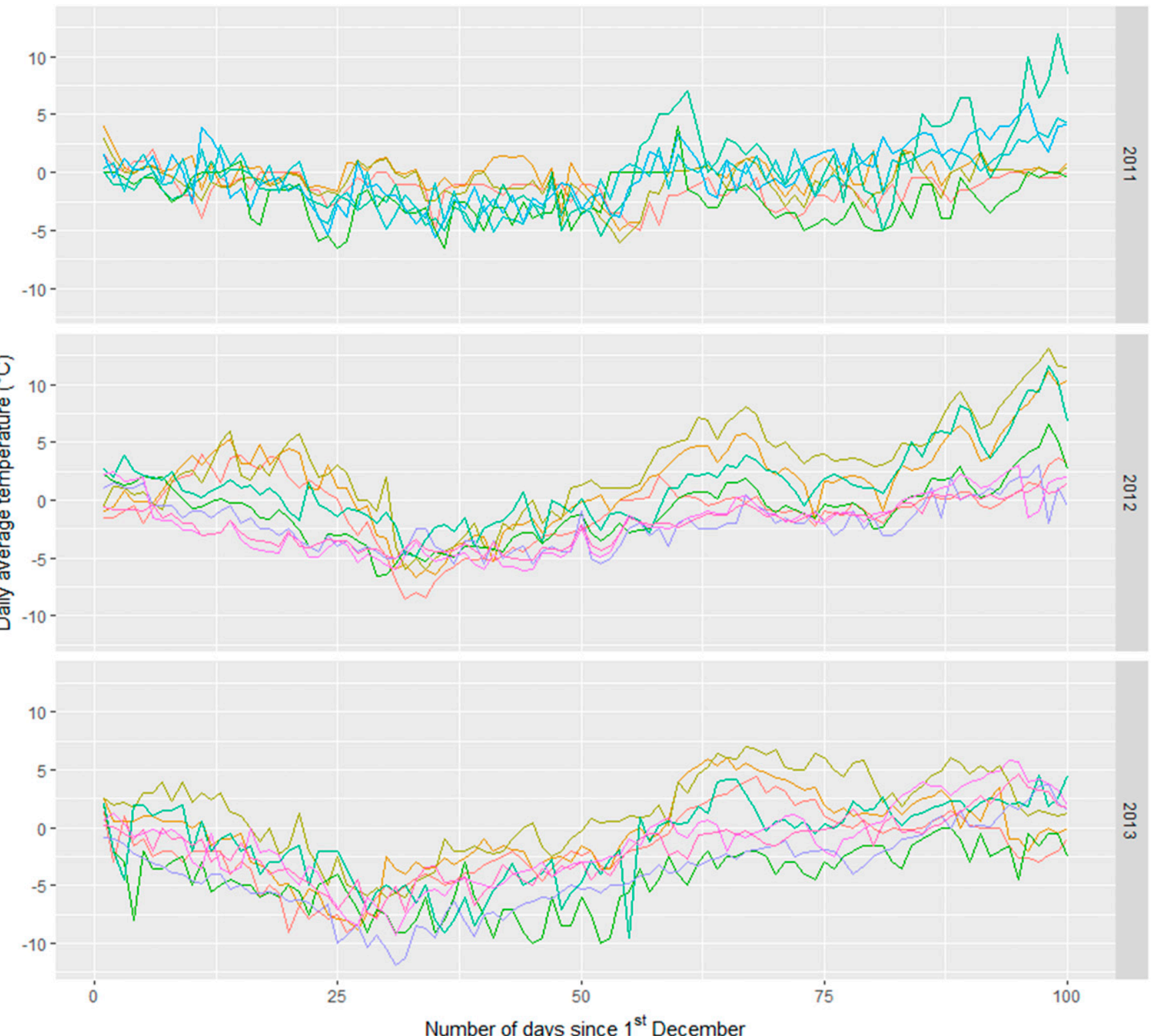

Fig. 1. Daily average temperatures from 1 December to 10 March in the following spring at the study sites in northwestern China in three growing seasons (2011-12, 2012-13, and 2013-14). 
Field inoculation of MX169 by $P$. striiformis f. sp. tritici. P. striiformis f. sp. tritici inoculum was multiplied in a controlled environment on MX169 seedlings in pots $(10$ by $12 \mathrm{~cm})$ containing cow dung compost and soil $(1: 2, \mathrm{vol} / \mathrm{vol})$. When the first two leaves were fully expanded ( 8 to 10 days after sowing), seedlings were inoculated with fresh urediniospores of the strain Chinese Yellow Rust (CYR) 32 (Li and Shang 1989), immediately placed in a dew chamber at 8 to $10^{\circ} \mathrm{C}$ in dark for $24 \mathrm{~h}$, then moved out to a greenhouse compartment $\left(10 \mathrm{~h} /\right.$ day at $17^{\circ} \mathrm{C}$ and $14 \mathrm{~h} /$ night $\left.14^{\circ} \mathrm{C}\right)$. Fresh urediniospores were collected from these inoculated leaves and stored in a desiccator at $4{ }^{\circ} \mathrm{C}$.

In mid-October, MX169 plants of two strips at each experimental plot were inoculated with the collected fresh urediniospores of $P$. striiformis f. sp. tritici CYR32. Plants were first sprayed with water to wet the leaves. Then, urediniospores were mixed with talcum pow$\operatorname{der}(1: 20, \mathrm{vol} / \mathrm{vol})$ in a glass testing tube $(0.5 \mathrm{by} 12 \mathrm{~cm}, 15 \mathrm{ml})$ that was covered with three layers of cotton gauze, and scattered over plants through gently tapping the testing tube ( $\mathrm{Li}$ and Shang 1989). Inoculated seedlings were immediately covered with black polythene to maintain high humidity conducive for infection. The cover was removed after $24 \mathrm{~h}$.

$P$. striiformis f. sp. tritici assessment in the autumn and spring. From late November to early December 2011, five points were randomly selected for each cultivar, and 40 plants at each point were then assessed for the presence of actively sporulating $P$. striiformis f. sp. tritici lesions. In the spring (late March), a number of plants (10 to 60) of each cultivar (Table 1) were randomly selected for assessment of actively sporulating $P$. striiformis f. sp. tritici lesions. Any sporulating lesion was unlikely to have resulted from new infections in the early spring and, hence, most likely originated from infections in the autumn.

In autumn 2012 and 2013, randomly selected plants with sporulating $P$. striiformis f. sp. tritici lesions at each site were labeled (Table 1). Immediately after $P$. striiformis f. sp. tritici assessment in the following spring, we dug tagged plants, took them back to the laboratory (Northwest A\&F University), transplanted the plants in pots, and assessed P. striiformis f. sp. tritici development 7 to 10 days later. For each cultivar at a given site, 12 and 30 labeled plants were assessed for $P$. striiformis $\mathrm{f}$. sp. tritici development in the glasshouse compartment in spring 2013 and 2014, respectively.

Data analysis. There were two measures for the proportion of plants with overwintered $P$. striiformis f. sp. tritici $\left(\mathrm{P}_{\mathrm{ow}}\right)$ : OW1 = $\mathrm{PS}_{\mathrm{S}} / \mathrm{PS}_{\mathrm{A}}$, where $\mathrm{PS}_{\mathrm{A}}$ and $\mathrm{PS}_{\mathrm{S}}$ were the $P$. striiformis f. sp. tritici incidences in the autumn and spring, respectively; and $\mathrm{OW} 2=\mathrm{PS}_{\mathrm{G}}$ / TPS, where $\mathrm{PS}_{\mathrm{G}}$ was the number of tagged plants with sporulating $P$. striiformis f. sp. tritici when assessed in the glasshouse after transplanting, and TPS was the total number of tagged plants transplanted in the spring.
For the 2011-12 season, $\mathrm{P}_{\mathrm{ow}}$ was estimated as OW1; for the 2012-13 and 2013-14 seasons, $\mathrm{P}_{\mathrm{ow}}$ was estimated as the average of OW1 and OW2.

We initially used windowpane analysis (Kriss et al. 2010; Pietravalle et al. 2003) first to determine the strength of correlation of $\mathrm{P}_{\mathrm{ow}}$ with temperature-derived variables and then to select appropriate time periods over which temperature was to be summarized for $\beta$ regression analysis.

Windowpane analysis. We constructed windowpane data from 1 December to 10 March of the following year to approximate the overwinter period. Summary temperature variables were calculated for windows of lengths $15,30,45$, and 60 days. Daily average temperature in each window was summarized into the following nine variables:

(i) Average temperature (Mean_T, ${ }^{\circ} \mathrm{C}$ )

(ii) Number of days with daily average temperature $\geq 0^{\circ} \mathrm{C}$ (DGT0) (iii) Degree days $>0{ }^{\circ} \mathrm{C}$ (MGT0)

(iv) Number of days with daily average temperature $<0^{\circ} \mathrm{C}$ (DLT0)

(v) Degree days $<0^{\circ} \mathrm{C}$ (MLT0)

(vi) Number of days with daily average temperature $<-2^{\circ} \mathrm{C}$ (DLT2) (vii) Degree days $<-2{ }^{\circ} \mathrm{C}$ (MLT2)

(viii) Number of days with daily average temperature $<-4^{\circ} \mathrm{C}$ (DLT4) (ix) Degree days $<-4^{\circ} \mathrm{C}$ (MLT4)

Temperature $<-4^{\circ} \mathrm{C}$ was not further subdivided because there were not many days with daily average temperature $<-4^{\circ} \mathrm{C}$.

The association between $\mathrm{P}_{\mathrm{ow}}$ and weather variables was quantified with the usual parametric correlation $(r)$ for each category of cultivar winter hardiness, pooling data across the 3 years. Thus, each correlation was determined from 23 data points. There is no simple solution to the fact that the test statistics are highly correlated for assessing the significance of windowpane correlation coefficients. We performed a global test of significance across for a given windowpane width using the Simes method (Simes 1986), testing for the global null hypothesis that none of the individual correlations is significant. Because the windowpane analysis was only used as a first step to select a time period for further regression analysis, we used two critical values $(\alpha=$ 0.005 and 0.001 ) purely for visual examination of the correlation strength.

Regression analysis. Because $\mathrm{P}_{\mathrm{ow}}$ was in the range of 0 to 1 , we used the $\beta$ regression model to establish the relationship of $P_{o w}$ to temperature-derived variables via a logit link function. The exact temperature variables (windowpane width and starting date) were determined by the initial windowpane analysis. For a given windowpane width and starting date, there were only nine temperaturederived variables. Thus, we used a backward selection method to

Table 1. Study sites and winter wheat cultivars for wheat stripe rust assessment in autumn and the following spring in the northwestern region of China in three growing seasons (2011-12, 2012-13, and 2013-14)

\begin{tabular}{|c|c|c|c|c|c|c|c|c|}
\hline \multirow[b]{3}{*}{ Site } & \multirow[b]{3}{*}{ Longitude } & \multirow[b]{3}{*}{ Latitude } & \multirow[b]{3}{*}{$\operatorname{Elev}(\mathbf{m})^{\mathbf{c}}$} & \multirow{2}{*}{\multicolumn{2}{|c|}{ Wheat cultivar ${ }^{\mathrm{a}}$}} & \multirow[b]{3}{*}{ Data $^{d}$} & \multicolumn{2}{|c|}{$\begin{array}{l}\text { Plants assessed } \\
\text { in the spring } b\end{array}$} \\
\hline & & & & & & & & 2012 and \\
\hline & & & & 2011 & 2012 and 2013 & & 2011 & 2013 \\
\hline Qinzhou A & $105^{\circ} 42^{\prime} 445^{\prime \prime}$ & $34^{\circ} 23^{\prime} 774^{\prime \prime}$ & 1,725 & MX169; XY22; XN979 & XY22; XN979; 1-314; LT91474a & 2011 & $10,20,20$ & 60 \\
\hline Qinzhou B & $105^{\circ} 42^{\prime} 418^{\prime \prime}$ & $34^{\circ} 24^{\prime} 293^{\prime \prime}$ & 1,627 & & & 2013 & $10,20,20$ & 60 \\
\hline Qinzhou C & $105^{\circ} 42^{\prime} 527^{\prime \prime}$ & $34^{\circ} 24^{\prime} 341^{\prime \prime}$ & 1,587 & & & 2011 & $10,20,20$ & 60 \\
\hline Lixian A & $105^{\circ} 16^{\prime} 550^{\prime \prime}$ & $34^{\circ} 12^{\prime} 795^{\prime \prime}$ & 1,532 & FS185; two other local cultivars & - & - & 50 & - \\
\hline Lixian B & $105^{\circ} 16^{\prime} 609^{\prime \prime}$ & $34^{\circ} 12^{\prime} 832^{\prime \prime}$ & 1,538 & & & - & 50 & - \\
\hline Zhuanglang A & $106^{\circ} 06^{\prime} 847^{\prime \prime}$ & $35^{\circ} 12^{\prime} 570^{\prime \prime}$ & 1,666 & TX46, two other local cultivars & XY22; XN979; 06-11; TX46 & 2013 & 50 & 60 \\
\hline Zhuanglang B & $106^{\circ} 00^{\prime} 475^{\prime \prime}$ & $35^{\circ} 09^{\prime} 737^{\prime \prime}$ & 1,543 & & & 2012 & 50 & 60 \\
\hline Guide & $101^{\circ} 25^{\prime} 141^{\prime \prime}$ & $36^{\circ} 01^{\prime} 873^{\prime \prime}$ & 2,226 & - & XY22; XN979; LT15; JN411 & 2013 & - & 60 \\
\hline Jianzha & $101^{\circ} 55^{\prime} 775^{\prime \prime}$ & $36^{\circ} 03^{\prime} 165^{\prime \prime}$ & 2,099 & & & 2013 & - & 60 \\
\hline Xunhua & $102^{\circ} 22^{\prime} 310^{\prime \prime}$ & $35^{\circ} 52^{\prime} 562^{\prime \prime}$ & 1,877 & & & 2013 & - & 60 \\
\hline
\end{tabular}

a Cultivars FS185, LT91474, TX46, LT26, LT15, and JN411 = strong winter hardiness; MX169 and XY22 = weak winter hardiness; and XN979, 01-314, and 06-11 = moderate winter hardiness. At the Lixian and Zhuanglang sites in 2011, one of the two local cultivars assessed was of weak winter hardiness and the other of moderate winter hardiness.

${ }^{\mathrm{b}}$ Only 10, 20, and 20 plants were assessed in the spring for MX169, XY22, and XN979, respectively.

${ }^{\mathrm{c}}$ Elevation in meters above sea level.

${ }^{\mathrm{d}}$ USB temperature data. 
select a "best" model; initially, by fitting a model with all nine variables (or maximum number of possible variables permitted with model fitting due to collinearity), then gradually reducing the number of variables until the best model was selected based on the percentage of variance explained, the pattern of residual errors, and collinearity among model variables. Because of large differences in the association of $\mathrm{P}_{\mathrm{ow}}$ with temperature (revealed by the windowpane analysis) among cultivars of different cold hardiness, $\beta$ regression was performed separately for each category of winter hardiness. The growing season (year) was used as a factor in the $\beta$ regression. All data analyses were carried out in $R$ (version 3.5.0) and $\beta$ regression was done by the betareg package (Cribari-Neto and Zeileis 2010).

\section{Results}

General observations. Analysis suggested that daily average temperatures recorded by the USB loggers are highly correlated with those recorded by the local stations: correlation coefficient is between 0.75 and 0.80 . Climatic conditions differed considerably between years. Overall, the 2013-14 winter was the coldest among the three seasons (Fig. 1). There were many days with daily average temperature $<-5^{\circ} \mathrm{C}$ for many sites in the $2013-14$ winter; in contrast, there were only a few days with daily average temperature $<-5^{\circ} \mathrm{C}$ for a few sites in the 2011-12 and 2012-13 seasons. For all sites, the coldest period was from the late December to late January (Fig. 1). The extent of daily temperature fluctuation differed considerably among sites. For instance, at Qinzhou A in 2011-12, the minimum and maximum of the daily amplitude was 0.5 and $5.5^{\circ} \mathrm{C}$, respectively, with an average of $2.2^{\circ} \mathrm{C}$. In contrast, at Qinzhou B in the same season, the corresponding values were 1 and $14.5^{\circ} \mathrm{C}$ (average $7.9^{\circ} \mathrm{C}$ ).

Average $\mathrm{P}_{\text {ow }}$ was similar between cultivars with different winter hardiness: 20,21 , and $18 \%$ for cultivars with weak, moderate, and strong winter hardiness, respectively (Fig. 2). However, the variability in $\mathrm{P}_{\mathrm{ow}}$ was the greatest and least for the cultivars with weak and strong winter hardiness, respectively-the corresponding variances were $0.032,0.020$, and $0.012 . \mathrm{P}_{\text {ow }}$ was higher in the 2011-12 (33\%) than in the 2012-13 (13\%) and 2013-14 (15\%).

Windowpane analysis. $\mathrm{P}_{\mathrm{ow}}$ was highly correlated with all the nine temperature-derived variables, particularly for cultivars of weak winter hardiness, but not for cultivars of strong winter hardiness (Fig. 3 ). Overall, the correlation was stronger for the period from midDecember to early February. Of the nine variables, the two related to temperature of approximately $0^{\circ} \mathrm{C}$ were least correlated with $\mathrm{P}_{\mathrm{ow}}$. The Simes test of windowpane correlation coefficients confirmed these findings (Fig. 4); none of the nine variables was significant for cultivars with strong winter hardiness.

$\boldsymbol{\beta}$ Regression analysis. $\beta$ Regression was performed separately for each category of winter hardiness. Based on the windowpane results, temperature was summarized for the period from 20 December to 18 January for cultivars with weak winter hardiness, and from 30 December to 28 January for cultivars with moderate and strong winter hardiness. Regardless of winter hardiness, the relationship of $\mathrm{P}_{\mathrm{ow}}$ with temperature-derived variables varied significantly with the season. Specifically, this relationship was similar between the 2012-13 and 2013-14 seasons but differed significantly from the 2011-12 season.

The summary of $\beta$ regression results is provided in Table 2 . For cultivars with both moderate and strong winter hardiness, $\mathrm{P}_{\mathrm{ow}}$ was not significantly related to any temperature-derived variable in the 2011-12 season but was negatively related to the duration when daily average temperature was $<-4^{\circ} \mathrm{C}$ for the other two seasons. For the cultivars with weak winter hardiness, $\mathrm{P}_{\mathrm{ow}}$ was significantly reduced by the increased duration when daily average temperature was $<-2{ }^{\circ} \mathrm{C}$ for all three seasons; however, the effect was much greater for the 2012-13 and 2013-14 seasons than for 2011-12 (Table 2). The model performance was the best and worst for the cultivars with weak and strong winter hardiness, respectively, based on the correlation between fitted and observed values (Table 2).

Interpretation of these models can be made on the basis of the odds-ratio because the logit was used as the link function in the $\beta$ regression. For instance, for the cultivars with weak winter hardiness, the odds ratio of successful $P$. striiformis f. sp. tritici overwintering is reduced by approximately $9 \%$ with one additional day with daily average temperature $<-2^{\circ} \mathrm{C}$ in the $2012-13$ or $2013-14$ season, and by $4 \%$ in the 2011-12 season. The relative decline of $\mathrm{P}_{\mathrm{ow}}$ is shown in Figure 5 in relation to the number days with average temperature $<-2^{\circ} \mathrm{C}$ in the period from 20 December to 18 January for cultivars with weak winter hardiness, and $<-4^{\circ} \mathrm{C}$ in the period from 30 December to 28 January for cultivars with both moderate and strong winter hardiness. P. striiformis f. sp. tritici survived the most and the least on the cultivars with strong and weak winter hardiness, respectively (Fig. 5).

\section{Discussion}

Understanding bottlenecks in pathogen survival is important for predicting disease onset and subsequent spread to other regions, and for developing and implementing integrated management strategies. Managing wheat stripe rust in oversummering and overwintering regions is a key component of sustainable stripe rust management strategies in China (Li and Zeng 2002). Based on field data, P. striiformis f. sp. tritici overwintering models were developed and these models can predict quantitative risks of $P$. striiformis $\mathrm{f}$. sp. tritici overwintering at specific sites.

The present study agrees with previous controlled studies showing that increasing cultivar winter hardiness leads to increasing survival of $P$. striiformis f. sp. tritici under low temperatures (Ma et al. 2015, 2017). This could be related to the reduced survival of leaves of cultivars with weak winter hardiness under low temperatures. However, $P$. striiformis f. sp. tritici mycelia inside leaves could be killed before leaves were killed under constant temperatures of -10 or $-20^{\circ} \mathrm{C}(\mathrm{Ma}$ et al. 2015). Previous controlled studies showed that differences in $P$. striiformis $\mathrm{f}$. sp. tritici overwintering between cultivars of different winter hardiness occurred mostly in the temperature range of 0 to $-10^{\circ} \mathrm{C}$ (Ma et al. 2015); most recorded temperatures during the winter in the present study sites were within this range.

$P$. striiformis f. sp. tritici survival under field conditions was much greater than that obtained under constant-temperature experiments. For instance, after $48 \mathrm{~h}$ at constant temperature of $-5^{\circ} \mathrm{C}$, only approximately 10,15 , and $20 \%$ of $P$. striiformis f. sp. tritici survived on

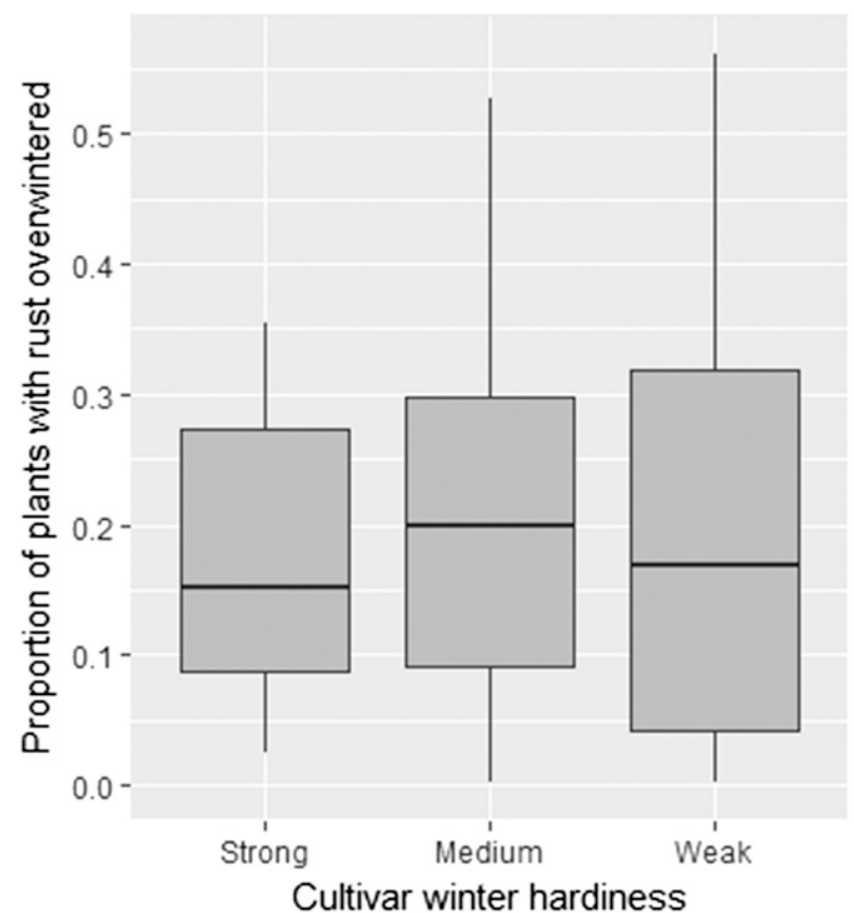

Fig. 2. Boxplot of the proportion of wheat stripe rust overwintered in the 2011-12, 2012-13, and 2013-14 seasons in northwestern China. In total, there were 23 site-year combinations (i.e., observations) for each winter hardiness category. 
cultivars with weak, moderate, and strong winter hardiness, respectively (Ma et al. 2015). In the present study, the fitted models predicted that approximately 10 and $40 \%$ of $P$. striiformis f. sp. tritici may survive for cultivars with moderate and strong winter hardiness, respectively, after 30 days with daily average temperature $<-4^{\circ} \mathrm{C}$. Most of this difference cannot be explained by the nonlinearity due to using daily average temperatures to predict $P$. striiformis f. sp. tritici survival. After $48 \mathrm{~h}$ under a fluctuating constant temperature of average $-5^{\circ} \mathrm{C}$ with a range of $8^{\circ} \mathrm{C}, P$. striiformis $\mathrm{f}$. sp. tritici survival ranged from 25 to $30 \%$ for cultivars with both weak and strong winter hardiness (Ma et al. 2017). Furthermore, the nonlinear effect is expected to be an issue only mostly for sites in the 2013-14 season, where daily average temperature was in the range of -4 to $-10^{\circ} \mathrm{C}$ on many occasions. Several other factors may partially account for this difference. First, results from controlled constant and fluctuating temperature studies may considerably underestimate $P$. striiformis f. sp. tritici survival in field conditions. Under the controlled studies (Ma et al. 2015, 2017), plants were subjected to sudden changes in temperature compared with field conditions. Thus, under field conditions, $P$. striiformis f. sp. tritici may be able to tolerate cold temperatures better than predicted by models developed from controlled studies. $P$. striiformis $\mathrm{f}$. sp. tritici may acclimatize to low temperatures when the gradient in temperature changes is small. Second, at some sites, winter snow cover may insulate the winter wheat and the pathogen from low temperatures (Sharma-Poudyal et al. 2014). Snow cover is generally not known to last for a long period of time
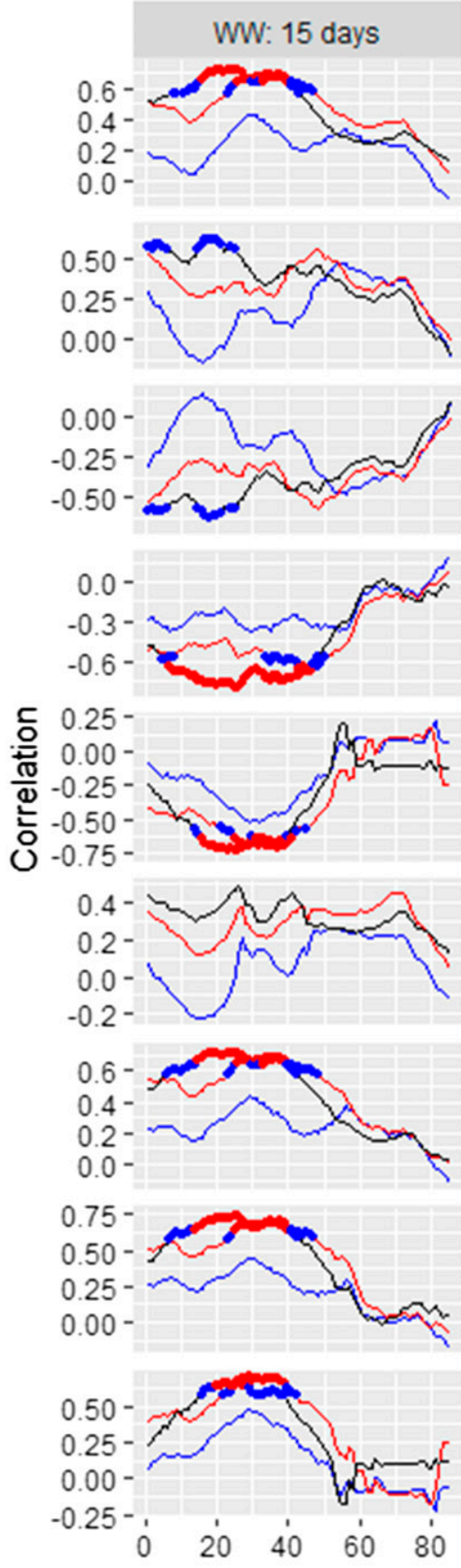
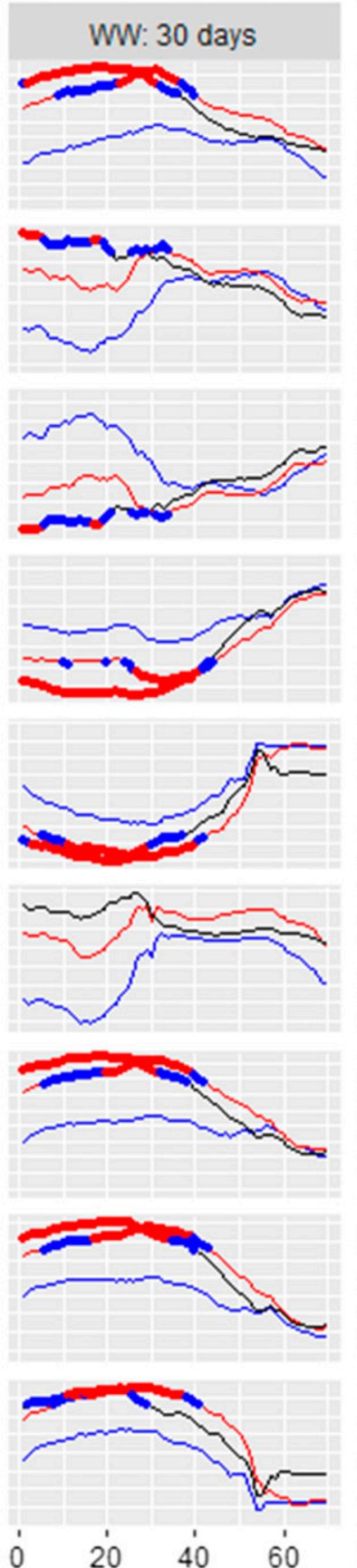
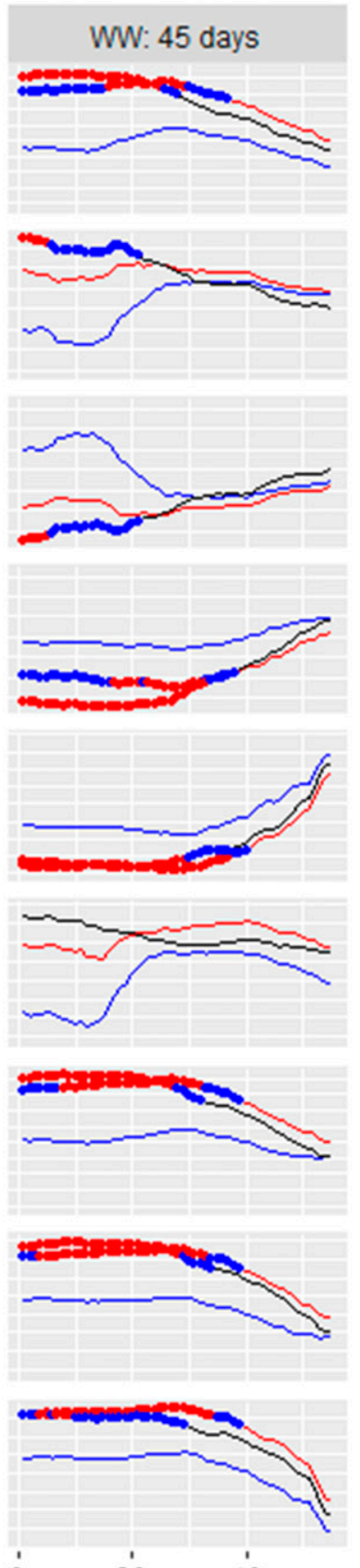

20
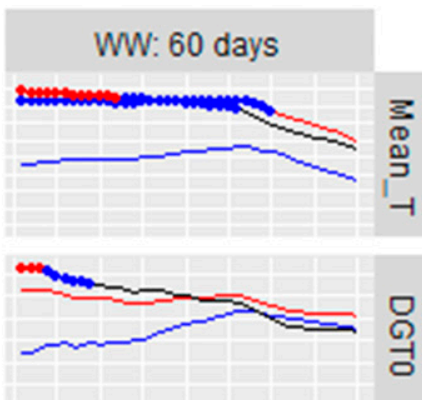

응
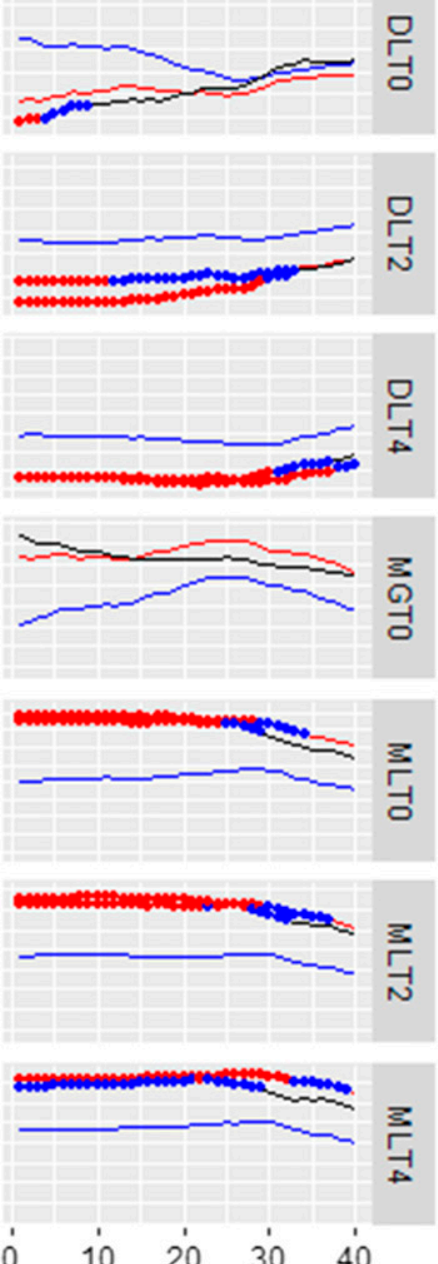

\section{Number of days since $1^{\text {st }}$ December}

Fig. 3. Pearson correlation coefficients at four window widths to assess the association between nine temperature-derived variables and the proportion of stripe rust overwintered in northwestern China in three seasons (2011-12, 2012-13, and 2013-14). Black line = cultivars of weak winter hardiness, red line $=$ cultivars of moderate winter hardiness, and blue line $=$ cultivars of strong winter hardiness; blue and red points $=P$ value of correlation $<0.005$ and 0.001 , respectively. 
in the sampling regions, particularly in Gansu Province. Finally, $P$. striiformis $\mathrm{f}$. sp. tritici may infect leaves even $<-4^{\circ} \mathrm{C}$ but remain symptomless in the winter (Burleigh and Hendrix 1970). Visual disease assessment in the autumn would not include these latent infections and, thus, may considerably underestimate the incidence of $P$. striiformis f. sp. tritici infections, leading to the overestimation of $P$. striiformis f. sp. tritici winter survival under field conditions.

The relationship between $P$. striiformis f. sp. tritici overwintering potential and temperature also differed between 2011-12 and the other two seasons: the survival in 2011-12 winter was either not dependent on temperature (for cultivars with moderate and strong winter hardiness) or much higher than in the other two seasons (for cultivars with weak winter hardiness). This is probably due to higher winter temperature at those sites in winter 2011-12 than in the other two seasons, particularly 2013-14. Only a few days were recorded with daily average temperature $<-4^{\circ} \mathrm{C}$ at a few sites in winter 2011-12. It is thus not surprising that we failed to define a clear relationship between $P$. striiformis f. sp. tritici winter survival and temperature for cultivars with moderate and strong winter hardiness. Therefore, the overall $P$. striiformis f. sp. tritici winter survival was much greater in the 2011-12 season than in the other two seasons. Differences in sampling methodologies should not have resulted in the observed differences between seasons. Using tagged plants to estimate overwinter potential is expected to give more accurate results; on average, the estimated $P$. striiformis f. sp. tritici overwintering potential based on the tagged plants was slightly greater than that based the disease assessment in the autumn and spring (16 versus $11 \%$ ). Thus, if we had used the tagged methods in the 2011-12 season as well, it might have led to even greater $P$. striiformis f. sp. tritici survival estimates. Fewer plants were sampled in 2011-12, which is expected to increase sampling errors but should not affect the magnitude of model parameter estimates. Considering all these points together, we would suggest that only the relationships derived from the 2012-13 and 2013-14 seasons should be taken forward.

The present models differ considerably from a previous model developed in the United States to predict $P$. striiformis f. sp. tritici overwintering potential in winter-wheat-growing regions (SharmaPoudyal et al. 2014). First, the U.S. model was developed based on the synthesis of many previous findings on several aspects of $P$. striiformis f. sp. tritici disease cycles. In contrast, we only used field observations in the northwest region of China to construct empirical models without explicitly considering specific disease cycles. The U.S. model included more explanatory variables. Most importantly, the U.S. model only predicts overwintering potential as categorical scores. In contrast, the present models predict the overwintering potential quantitatively, on a continuous scale of 0 to 1 . The models are easy to interpret based on the odds ratio. In addition, our models also consider the effects of cultivar winter hardiness on $P$. striiformis $\mathrm{f}$. sp. tritici overwintering potential.

In summary, $P$. striiformis $\mathrm{f}$. $\mathrm{sp}$. tritici overwintering is primarily affected by the duration of low temperatures in the coldest period from late December to late January. The derived logistic models

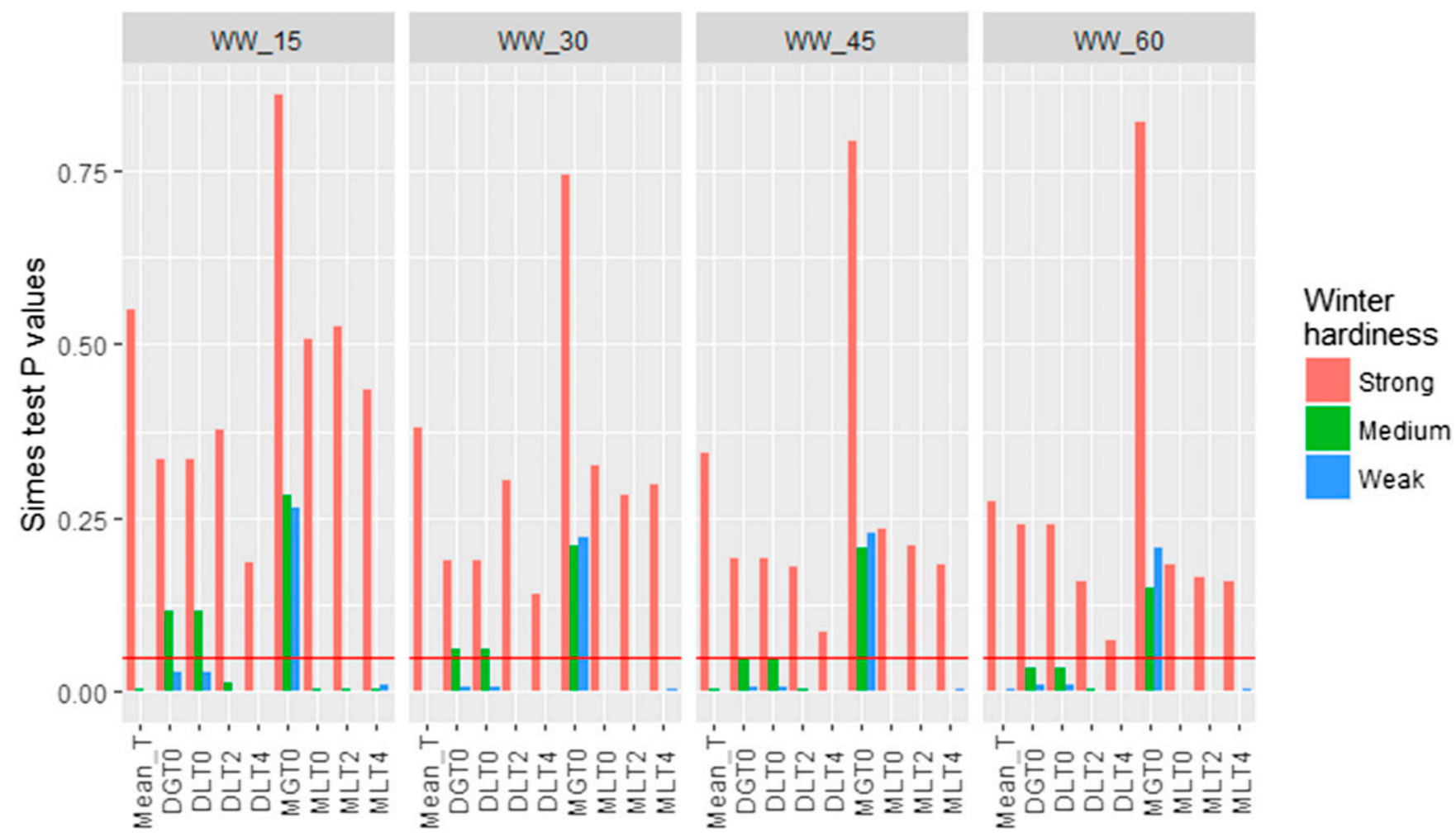

Fig. 4. Simes test for the overall significance of multiple nonindependent correlation coefficients from windowpane analysis. The horizontal line indicates $P=0.05$.

Table 2. Regression results for proportion of overwintered wheat stripe rust in the northwestern China in three seasons (2011-12, 2012-13, and 2013-14) ${ }^{\mathrm{a}}$

\begin{tabular}{lllc}
\hline Cultivar winter hardiness & \multicolumn{1}{c}{ 2011-12 } & \multicolumn{2}{c}{$\begin{array}{c}\text { Co12-13 and 2013-14 } \\
\text { (fitted versus observed) }\end{array}$} \\
\hline Weak & $-0.044( \pm 0.016) \bullet$ DLT2 & $-0.095( \pm 0.011) \bullet$ DLT2 & 0.814 \\
Moderate & $-0.750( \pm 0.246)+0.018( \pm 0.061) \bullet$ DLT4 & $-0.750( \pm 0.246)-0.087( \pm 0.0198) \bullet$ DLT4 & 0.775 \\
Strong & $-1.411( \pm 0.267)+0.096( \pm 0.065) \bullet$ DLT4 & $-1.411( \pm 0.267)-0.039( \pm 0.020) \bullet$ DLT4 & 0.647 \\
\hline
\end{tabular}

${ }^{\mathrm{a}}$ In $\beta$ regression, logit was used as the link function. DLT2 and DLT4 = average number of days with average temperature less than -2 and $-4^{\circ} \mathrm{C}$, respectively, in the window width. For cultivars with weak winter hardiness, DLT2 was calculated for the period of 20 December to 18 January whereas, for cultivars with moderate and strong winter hardiness, DLT4 was calculated for the period of 30 December to 28 January. Numbers in parentheses indicate the standard error of the corresponding parameter estimate. 


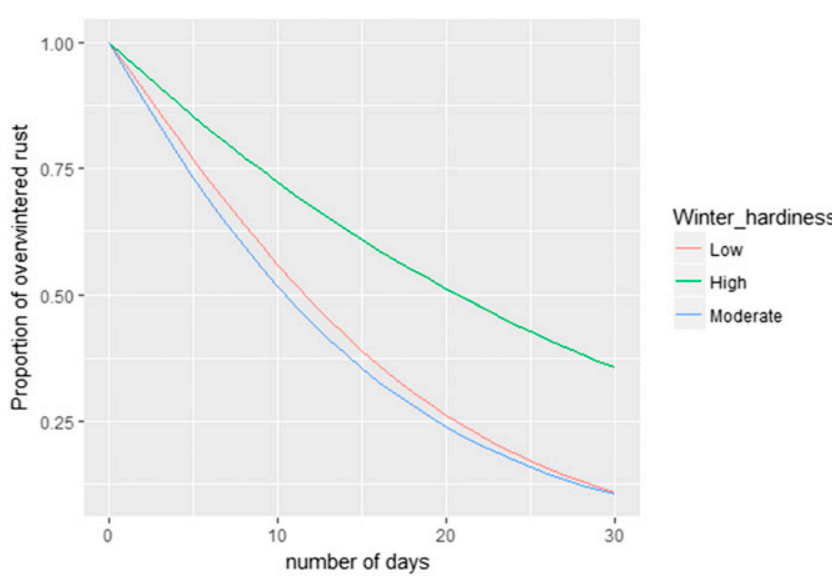

Fig. 5. Fitted logistic models describing the proportion of overwintered wheat stripe rust in relation to the number of days with average temperature $<-2^{\circ} \mathrm{C}$ from 20 December to 18 January for cultivars with weak winter hardiness, and $<-4^{\circ} \mathrm{C}$ from 30 December to 28 January for cultivars with both moderate and strong winter hardiness. All values were divided by the maximum value of each series (i.e., at 0 days) for ease of comparison.

fitted the observed data satisfactorily. P. striiformis f. sp. tritici survival in low temperatures under field conditions is much greater than predicted from controlled studies. $P$. striiformis f. sp. tritici overwintering may be affected by gradient changes in temperatures, which needs further research. The present models can be further improved by incorporating snow cover and possibly the wind chill effect (Ma et al. 2016). Further independent validation is also necessary before they can be used in practice with confidence.

\section{Literature Cited}

Burleigh, J. R., and Hendrix, J. W. 1970. The winter biology of Puccinia striiformis West, in the Pacific Northwest. Tech. Bull. Agric. Exp. Stn. 65.

Chen, X. M. 2005. Epidemiology and control of stripe rust on wheat (Puccinia striiformis f. sp. tritici). Can. J. Plant Pathol. 27:314-337.

Coakley, S. M., Boyd, W. S., and Line, R. F. 1982. Statistical models for predicting stripe rust on winter wheat in the Pacific Northwest. Phytopathology 72: $1539-1542$.

Coakley, S. M., and Line, R. F. 1981. Quantitative relationship between climatic variables and stripe rust epidemics on winter wheat. Phytopathology 71 : 461-467.

Coakley, S. M., Line, R. F., and McDaniel, L. R. 1988. Predicting stripe rust severity on winter wheat using an improved method for analyzing meteorological and rust data. Phytopathology 78:543-550.

Cribari-Neto, F., and Zeileis, A. 2010. Beta regression in R. J. Stat. Softw. 34:1-24.

Fang, S., Tan, K., Ren, S., Zhang, X., and Zhao, J. 2012. Fields experiments in North China show no decrease in winter wheat yields with night temperature increased by $2.0-2.5^{\circ} \mathrm{C}$. Sci. China Earth Sci. 55:1021-1027.
Gladders, P., Langton, S. D., Barrie, I. A., Hardwick, N. V., Taylor, M. C., and Paveley, N. D. 2007. The importance of weather and agronomic factors for the overwinter survival of yellow rust (Puccinia striiformis) and subsequent disease risk in commercial wheat crops in England. Ann. Appl. Biol. 150:371-382.

Grabow, B. S., Shah, D. A., and DeWolf, E. D. 2016. Environmental conditions associated with stripe rust in Kansas winter wheat. Plant Dis. 100:2306-2312.

Kriss, A. B., Paul, P. A., and Madden, L. V. 2010. Relationship between yearly fluctuations in Fusarium head blight intensity and environmental variables: A window-pane analysis. Phytopathology 100:784-797.

Li, Z. Q., and Shang, H. S. 1989. Wheat Rust and Their Control. Shanghai Science and Technology Press, Shanghai, China.

Li, Z. Q., and Zeng, S. M. 2002. Wheat Rust in China. China Agricultural Press, Beijing, China.

Ma, L., Hu, X., and Xu, X. 2017. Effect of controlled fluctuating low temperatures on survival of Puccinia striiformis f. sp. tritici. Eur. J. Plant Pathol. 147: 713-716.

Ma, L., Kong, X., Qiao, J., An, F., Hu, X., and Xu, X. 2016. Overwintering of Puccinia striiformis f. sp. tritici on winter wheat at varying altitudes in Gansu and Qinghai Provinces. Plant Dis. 100:1138-1145.

Ma, L., Qiao, J., Kong, X., Zou, Y., Xu, X., Chen, X., and Hu, X. 2015. Effect of low temperature and wheat winter-hardiness on survival of Puccinia striiformis f. sp. tritici under controlled conditions. PLoS One 10:e0130691.

Ma, Z. H., Shi, D. S., Jiang, Y. Y., and Zhao, Z. H. 2005. Climate-based regional classification for oversummering of Puccinia striiformis in China with GIS Acta Phytopathol. Sin. Chin. 34:455-462.

Pan, G., Chen, W. Q., Liu, T. G., Gao, L., Cao, S. Q., and Wang, X. M. 2011. Survey of overwintering Puccinia striiformis f. sp. tritici at different altitudes in the areas of Tianshui, Gansu province. Plant Prot. Chin. 37:103-106.

Papastamati, K., and van den Bosch, F. 2007. The sensitivity of the epidemic growth rate to weather variables, with an application to yellow rust on wheat. Phytopathology 97:202-210.

Pietravalle, S., Shaw, M. W., Parker, S. R., and van den Bosch, F. 2003. Modeling of relationships between weather and Septoria tritici epidemics on winter wheat: A critical approach. Phytopathology 93:1329-1339.

Sharma-Poudyal, D., Chen, X., and Rupp, R. A. 2014. Potential oversummering and overwintering regions for the wheat stripe rust pathogen in the contiguous United States. Int. J. Biometeorol. 58:987-997.

Sharma-Poudyal, D., and Chen, X. M. 2011. Models for predicting potential yield loss of wheat caused by stripe rust in the U.S. Pacific Northwest. Phytopathology 101:544-554.

Sharp, E. L., and Hehn, E. R. 1963. Overwintering of stripe rust in winter wheat in Montana. Phytopathology 53:1239-1240.

Shen, Q. Y., and Wang, K. N. 1962. Research status and future directions on epidemiology of wheat stripe rust in China. Acta Phytophylac. Sin. Chin. 1:393-402.

Simes, R. J. 1986. An improved Bonferroni procedure for multiple tests of significance. Biometrika 73:751-754.

Te Beest, D. E., Paveley, N. D., Shaw, M. W., and van den Bosch, F. 2008. Disease-weather relationships for powdery mildew and yellow rust on winter wheat. Phytopathology 98:609-617.

Wang, H., Yang, X. B., and Ma, Z. 2010. Long-distance spore transport of wheat stripe rust pathogen from Sichuan, Yunnan, and Guizhou in Southwestern China. Plant Dis. 94:873-880.

Yao, Q., Guo, Q. Y., Yan, J. H., Zhang, G., Hou, S. Y., and Chen, W. Q. 2014 Survey on overwintering Puccinia striiformis f. sp. tritici at different altitudes in eastern Qinghai. Acta Phytophylac. Sin. Chin. 41:573-578.

Zeng, S. M., and Luo, Y. 2006. Long-distance spread and interregional epidemics of wheat stripe rust in China. Plant Dis. 90:980-988. 